\title{
Digital personal stories: bringing together generations and enriching communities
}

\section{Natalia Kucirkova, The Open University}

\section{Building community narratives}

This chapter draws on a community project 'Remember' which explored the potential of digital personal stories to support cross-setting and intergenerational dialogue. Over six months, children in two Year 4 classrooms interviewed local people about their WWII experiences and documented these in writing, pictures and audio, using an iPad app called 'Our Story' and additional web-based resources from a local archive. Story-sharing and collection of personal digital materials were facilitated by AirWatch software which enabled safe story-sharing across formal and informal learning contexts. Digital personalised stories were later shared at a local event and online with the wider community. The chapter considers how intergenerational collaborative community projects might enrich children's engagements with the past, how new technologies can mediate sharing of authentic community narratives and facilitate meaningful intergenerational and cross-setting interactions.

\section{Rationale for the project}

Practices and research efforts to promote use of digital technologies in the school context have historically focused on the educational benefits for children (see Roschelle, Pea, Hoadley Gordin, \& Means, 2000) or on the pedagogical practices for teachers (e.g., Mishra \& Koehler, 2006). This project highlights the need for developing research concerned with wider community issues and that which bridges the learning processes and interests of various stakeholders, including children and their parents, teachers, elderly community members, as well as the technological partners providing, designing or facilitating the use of technology in schools, homes and the community.

It is beyond the scope of this chapter to provide a systematic description of the complex processes at play in a rich community project and to tackle the complex theoretical as well as philosophical debates in relation to technology and communities. Instead, I spotlight the role of authentic community narratives and technological innovation for story-sharing. Specific attention is paid to the value of new technologies in bridging intergenerational differences in technology use and fostering digital story-telling skills.

The chapter begins with an overview of some key studies in this area and the main theoretical and practical challenges addressed in the project, including a theoretical framework for intergenerational digital literacy, the value of community narratives and local stories in the age of the Internet and the use of technologies to enable intergenerational dialogue and community engagement. I then describe the iPads and Our Story app used to collect and share stories in the project - and their particular affordances in relation to the project objectives. The remainder of the chapter captures the essence of the process of children's collection and editing of stories, and intergenerational learning happening in the community. The discussion focuses on the blurring between past/present and personal/community which were evident in the data.

\section{Theoretical framework for intergenerational digital literacy}

The chapter works from the assumption that literacy development relates not just to individual internal processes but that wider environments mediate our understanding of literacy, communication and meaning-making. In doing so, it focuses particularly on the role of adults (including elderly members of the community) as co-learners. Emphasis is laid on 
authorship, creation and sharing of knowledge, with technology largely facilitating the process of expertise development. This perspective on knowledge construction highlights the importance of cultivating learning environments which support collective, shared and dynamic learning communities rather than autonomous problem-solvers. Learning is viewed as a process of creating transformational and evolving thoughts, and successful learning environments are contemplated at collective and organizational levels (Bereiter and Scardamalia, 2005).

\section{Community narratives}

Community narratives are narratives which define a certain group, or community, of people, and they 'serve as the context for personal stories' (p.21, Nettles, 2005). The value of, and need for, community narratives has been reported in various strands of literature. Community narratives are often reconstructed from local stories shared orally or stored visually in a local archive (such as a local museum) or in private family collections. Understanding how authentic community narratives are developed, captured and propagated, is a key methodological challenge. Thus far, researchers have explored community narratives through various qualitative approaches, with the focus often being placed on underrepresented or minority communities. There has been an interest in exploring community narratives that already exist, finding new ways of sharing community narratives, or working with communities to generate new narratives. For example, Humphreys (2000) used ethnographic approaches to study the personal and community narratives of members of Alcoholics Anonymous, while Renando (in preparation) explored positive lived-experiences of Christians in the West using an innovative arts-based digital approach to narrative creation. Other projects have focused on the patterns of narratives in families and intergenerational connections, particularly in multicultural communities. Campano (2007), for example, sought to understand the value of community narratives of immigrant students in North America in order to support students to make connections between community narratives and their schooled experience. There are also studies which examine effective ways for connecting families to harness their cultural and linguistic resources within existing social systems (e.g., Genishi \& Dyson 2009). These projects share a commitment to fostering intergenerational dialogue and engaging young children in learning from elders and vice versa.

\section{The value of intergenerational learning}

Several innovative projects have used technology to foster intergenerational dialogue. In exploring the value of intergenerational learning Gregory describes the ways in which young children develop important literacy practices through intergenerational interactions (e.g. Gregory, 1996; Gregory, Long \& Volk., 2004). Drawing on her extensive study of the Bangladeshi community in London, Gregory (1996) describes how young children's learning from their peers, siblings and grandparents, contributed to the children's bilingual learning, their construction of identity and communication skills. Heydon has explored how such interactions can be fostered and enriched using visual texts (Heydon, 2005; 2007). Recently, McKee and Heydon (2015) explored the use of technologies in an Intergenerational Digital Literacies Project, in which technologies (iPads) acted as a vehicle to expand the literacy and identity options for children and elders. Drawing on multimodal literacy theory (Kress, 2007) and a conceptualization of literacy as a social practice (Vygotsky, 1987), they studied how a combination and variety of modes and media, including visual and digital media, can engage partners in sharing songs and narratives. McKee and Heydon (2015) note in their research findings that during an intergenerational session between a child and an elder participant, 'the use of the iPad allowed children and elders to collaborate as equal partners within the meaning-making process' (p. 236). Our 
project aimed to build on this intergenerational work by foregrounding the technological possibilities of iPads in supporting the development and sharing of community narratives as embedded in the practices of the elderly, children, teachers and other community members.

\section{Tablets enabling intergenerational dialogue and community engagement}

In schools, the use of new technologies has often been studied for its potential to nurture individual skills, such as children's computational thinking (see Grover \& Pea, 2013), digital literacy (e.g., Ba, Tally, \& Tsikalas, 2002) or print-related literacies (e.g., Tuzun et al., 2009). Tablets and computers are in these scenarios used primarily in dyadic or individual contexts. While such opportunities play an important role in the learning trajectory of individual learners, it is also important to recognise the social role technology can play in learning and its potential to foster dialogue and sharing of narratives in the community.

Notably, the ways in which technologies can connect communities and enrich intergenerational relationships is an exciting new line of research. In our project, we focused on a iPads, currently very popular in Western classrooms: the iPad. iPads are flexible, portable and multi-featured devices that offer the possibility to run a number of applications (software programs). Since early 2010s, iPads have gained great popularity as a tool for education as well as entertainment at home and in school. iPads fuse several technologies into one device, including a digital camera, keyboard for typing, and audio-recorder. As such, they have the potential to engage children multimodally (i.e. via touch, vision and sounds) and sequentially (i.e. with gradually increasing levels of difficulty). These characteristics of iPads exemplify the potential of technologies to foster not a single literacy but multiple literacies (Jewitt, 2008).

Emerging research shows that children can "play their way into literacies" with popular media (Wohlwend, 2012) and that iPads in particular, can foster the development of literacy skills (Falloon, 2013) and provide meaningful literacy experiences for pre-school children and children with emerging language (Kucirkova, Messer, Sheehy \& Panadero, 2014) or limited language (Flewitt, Kucirkova \& Messer, 2014). Clearly, different apps will support children's learning to a different extent (see Marsh et al, 2015). This study utilised an app called Our Story we have been developing since 2011.

\section{The Our Story app}

Our Story (http://www.open.ac.uk/creet/main/projects/our-story) builds on the theory of personalisation (Oulasvirta \& Blom, 2008) and research concerned with effective shared book reading (Whitehurst et al., 1994). Over the past five years, the app has been used in various contexts to support children's reading engagement at home (Kucirkova, Messer, Sheehy \& Flewitt, 2013) and classroom dialogue (Kucirkova, Messer, Sheehy \& Panadero, 2014). We have used a participatory research methodology through which participating schools have been pivotal for the design testing and iterative development of the app. The app is freely available as an educational resource from the App store and Googlemarket store.

Our Story has two main modes of engagement: the "Create" and the "Use" mode. In the Create mode, users can add their own pictures (either downloaded on the device or taken with the iPad embedded camera), sounds and texts. There is also a gallery of pictures where users can upload their own photographs from the camera roll or download pictures from the Internet. There is a filmstrip at the bottom of the screen which can be used to arrange pictures in a sequential order to create a multimodal book. The "Our Story books" are not traditional or electronic books, diaries or photo albums. Rather, they could be perceived as a blend of old and new affordances of book media for capturing past and present experiences 
and authentic story-making practices. Users can easily add, edit or remove text and pictures during the actual activity of story sharing. The iPad camera and audio-recorder make the visual and audio material immediately accessible and amendable in the moment of sharing, which may have consequences for the there-and-then as well as anticipated future interactions. For instance, a played sound of the narrator's voice recorded in the past can be replayed in the present and extended by including a comment by the child, or it can be deleted and left blank to be completed in the future. Alternatively, a pre-recorded spoken sound can be changed to a song or a soundtrack of the user's choice, as the user can access his or her favourite tune impromptu, using the online access option inbuilt in the iPad. Similarly, a picture in the story can be changed to a different picture, taken and inserted almost instantaneously in the moment of story reading, using an in-built camera or any webbased picture depository. The same responsiveness applies to the written text accompanying each story: with keyboards instantly accessible through the app, making both the reading and writing experience responsive to the 'in the moment' story sharing. A story created (written and narrated) at an earlier time can therefore be altered at the moment of sharing- and this transformation can occur in three different modalities (written, audio and visual).

In Use mode, Our Story users can share their story using a variety of options. They can share the story by reading it in on the iPad (the finished story is presented page by page with the sound being played automatically) or they can share their stories remotely. For the latter, users can choose from the options of emailing the finished story to their friends or families or sharing it as a printed version. If they decide to print the story, there are three printing sizes available (A4, A5 and A6).

A particular advantage of using Our Story in intergenerational and community projects is its possibility to support authentic community narratives. Although technologies can facilitate recording of community narratives, it remains a practical challenge for researchers to capture community narratives in a way that would preserve their authentic character. There is a danger that community engagement and its portrayal becomes tokenistic and overlooks the authentic nature of intergenerational dialogue. Authenticity is a much used term, with many meanings. In our project, authenticity was understood from a psychological perspective which distinguishes between behavioural (directly observable) and mental (emotional) authenticity. Roberts (2014) defines authenticity as 'a psychological and behavioural process whereby an individual lives in accordance with the true self' (p.1) and specifies four key elements which operate within this process: self-knowledge, selfawareness, self-regulation, and authentic behaviour. In this project, the pursuit of "authenticity" in community narratives happened on both communal and individual level and was aided by two key characteristics of the Our Story app: 1, its open-ended design and 2, combination of multimedia. There are no templates in the app, users can create any stories they like. This means that there is no need to circumvent or limit participants' narratives, they are in control and can regulate the exact nature of what is captured from their personal account and what is shared with others.

We were keen to leverage the open-ended affordances of the app and in addition to using Our Story, we used AirWatch technology (http://www.airwatch.com/solutions/education/) in this project. AirWatch offers an enhanced, technologically robust and secure way of content sharing on tablets. This was crucial at a later stage of the project where parts of multimedia needed to be shared seamlessly and securely across various devices of participating children and community members.

\section{The project:}




\section{Project partners}

There were several partners in the project, including the technology company Aerohive (a networking company) and Book Trust (UK's largest literacy charity). Their role was crucial in ensuring a smooth run of the project but was not central to the intergenerational story sharing which is described in this chapter. For this purpose, four partners were crucial in the project: the participating school (Swallowfield Lower School), the Open University researchers, the Community project created by Churches Together in Woburn Sands called Love Woburn Sands and the technology company AirWatch. All partners were keen to engage in a project within the local community and leverage their geographical proximity (all partners are based in Buckinghamshire). All partners shared a synergistic commitment to creating innovative products and learning environments, which leverage the power of new technologies to foster personalised education and connect local communities through personal stories. There was thus a mutually-enriching relationship between the partners, with the school positioned at the centre, as a "hub" for all the relationships.

\section{Project details}

The collaboration between the school partners continues and a new collaborative endeavour is currently in the planning stages. In this chapter, I describe the Remembrance project which took place in 2014/2015. For this project, the school, and where appropriate, the community participants, were provided with free access to the AirWatch mobile device security system and additional iPad hardware (on loan from the Open University).

Over the course of six months, two classes of 8-9 year olds engaged in the creation of personalized multimodal stories on the topic of Remembrance, using the OU-developed Our Story app and additional web-based resources (including resources provided by the local archive of photographs). The community partner Love Woburn Sands provided access to community members interested in the project and paired them up with the participating classrooms. The OU team provided guidance and necessary support on using the Our Story app and aligning story-making techniques with curriculum objectives. The researchers acted as participant observers and employed ethnographic methods for data collection. AirWatch software facilitated secure and efficient storage and transfer of personal digital content.

The theme of Remembrance provided a coherent frame for children's stories and was broadly conceptualised to include the topics of memory, World War II and local heritage. The development of authentic community narratives proceeded in various stages:

First, the children planned their interviews with the community members. Together with their teachers, they drafted some questions and read over the interview protocol. On a day mutually convenient for the interviewees and the school, the children interviewed elderly members of the community about their WWII experiences such as being evacuated, bombed out and living with new families. Children audio-recorded the interviews but also took notes and photographs of the interviewees and various artefacts they brought to the interview (e.g., personal objects they had kept from the war). After the interview, children reviewed the data they collected and planned their stories on paper. Photographs were matched with transcribed sentences and enriched with information children found online. This process was followed by editing on the iPad, with children combining short audio recordings with text captions and digital photographs into multimodal assemblages. (See Figure 1.) This part of the editing process was facilitated with the Our Story app. So, unlike in McKee \& Heydon's study (2015), the elders did not work together with the children on the stories, but they recounted their experiences and watched children putting them together on the iPad. However, many of them were familiar with the technology because of a sister project at the adjacent school 
where children taught IT skills to adults. Finished stories were shared at a school assembly orally and as printed booklets with pictures and texts put together by the children.

\section{Figure1:Prints of the finished stories created with Our}

Story

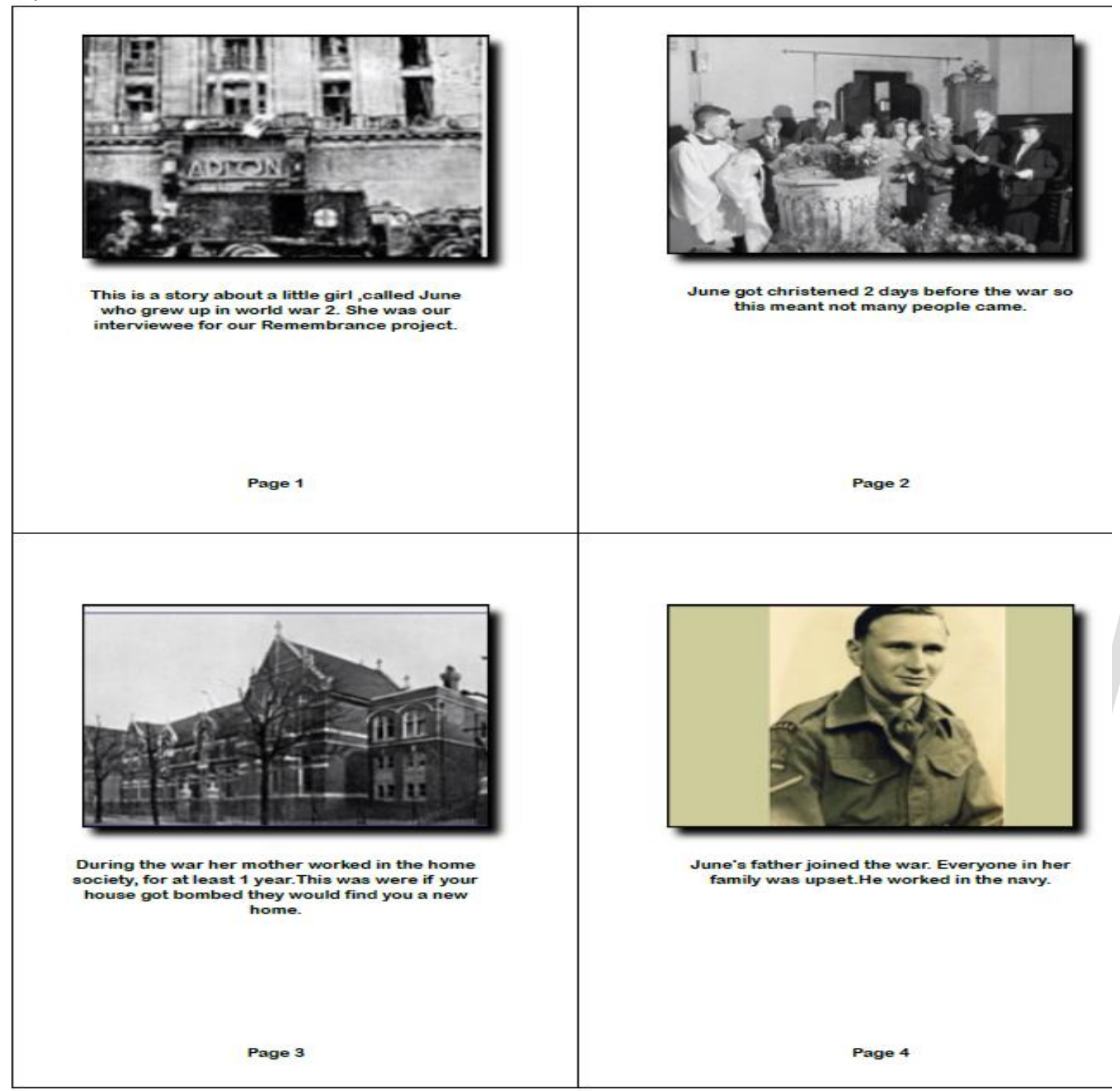

Our approach to the data collection was qualitative, seeking to understand, at a level of detail, how a digitally-mediated intergenerational story-sharing technique worked in the community and how it was perceived by the participants (the teachers, children and the elderly participants). Data collection included videotaping classes, interviews with the teachers (informal recorded through field notes as well as audio-recorded); interviews with the children and community members participating in the project; video-stimulated interviews with the team members. We also analysed the stories (in printed and multimedia formats) children have created and shared during the project. These complementary data sets were analysed in response to several research questions linked to the community aspect of storysharing; to innovation in a primary school facilitated with new technologies and to the multimedia ways of capturing personal narratives. In this chapter, I focus on the role of technologies in mediating the creation and sharing of authentic community narratives and 
meaningful intergenerational dialogue. This inquiry is guided by the question: How did the use of iPads mediate the creation and sharing of authentic community narratives?

\section{Intergenerational narratives}

This section captures the interview discussion with the teachers and our in-situ observations of what children learnt during the project. The teachers commented on children's high levels of engagement in the project and the ways in which the interviews with elderly community members "brought history to life" and enabled children "to have a dialogue" with other members of community. It was evident that the possibility to share personal narratives with the Our Story app fostered meaningful intergenerational exchanges. For children, the possibility to record the narratives with new technology was appealing and motivating. The elderly too, were motivated and keen to make their narratives as rich as possible by adding further detail, patiently answering children's questions and bringing personal artefacts to further illustrate their experiences.

The extent to which this enthusiasm came about was no doubt influenced by the fact that the children and elderly could see their memories "come alive" in historic pictures, audio recordings and short stories captured by the Our Story app. The gradual process of seeing the story "grow" from an oral account to audio-recording and finally text and a string of letters, enriched children's understanding of how individual layers and aspects of a story can come together as a multimedia amalgam. Children were actively making choices about how to assemble the individual ingredients for their stories. The iPads thus served here the role of equipping children to become "competent techno-citizens" (Marsh, 2002, p.137) who use new technologies not merely to consume but also to collaboratively produce new content. In the following vignette based on video footage, I highlight the role of the iPads (and the Our Story app) in how such use of technology enriched children's engagements with the past.

Mark, Julia and Alex sit around one of the five small tables in the classroom, closely huddled around an iPad2, loaded with Our Story. There are also pencils, scissors, crayons, sticky notes, cardboard and paper on the table. The children have finished drafting the storyboard on one of the bigger sheets of paper, and are now scrolling through the camera roll on the iPad. 'This one!' Julia shouts enthusiastically and drags a black-and-white picture into the storyboard. The picture was downloaded from the Internet and depicts an old house with blurred contours. Julia uses it to complement a sequence of pictures showing a story of one of the elderly they interviewed. Mark is not happy with the picture and drags it back to the picture bank with his middle finger: He scrolls down the gallery and locates a picture of an elderly woman sitting in front of a house. He smiles and says to Julia and Alex: 'That's her, look!' Julie and Alex watch him attentively and let him drag the new picture onto the storyboard. Alex turns the iPad towards and taps the microphone button: 'I do the sound', he says and starts recording a short passage previously drafted with his peers.

Examples of collaborative working were evident also in the classroom in that children worked in pairs or small groups when editing their stories with the Our Story app. Collaboration thus happened on two levels: between the children and the elderly, and between peers in the classroom. The multimedia stories were personally relevant, not off-theshelf reports reproducing curriculum material. The teachers recognised this potential and talked during interviews about how such collaboratively produced content can act as a vehicle for teaching social skills (e.g., importance of story-sharing) and support moral reasoning (e.g., citizenship, which was one of the topics they explored at school level that 
month). On a wider level, observing collaboration among the project participants was encouraging for us, researchers and project partners, as it reflected the collaborative ethos of the project itself.

\section{Recontextualising Rememberance with new technological tools}

Like McKee \& Heydon (2015), we found that iPads facilitated the story-creation and story-sharing process. Our Story was useful in capturing the stories shared by the elderly and together with the AirWatch technology, the app enabled children and teachers to securely store personally sensitive data and share them with selected users in the community. As such, technologies enabled cross-contextual story-sharing and offered a unique opportunity to develop intergenerational dialogue not only immediately in this project but also for future generations. For example, data from the repository of resources in the local archive could be flexibly and coherently used in the present project, but also to be stored and re-used in subsequent years.

This highlights the advantages of re-contextualising a traditional subject Remembrance with new technological tools such as iPads and personalised multimedia stories. Each year, the school focuses the English and History classes around Remembrance, with activities culminating on the 11 th November, Remembrance Day ${ }^{1}$. Key issues typically discussed in the classroom include reflection on the tragedy of war, and discussion on how conflict and flight can be avoided and how war victims might be supported. Over years, teachers have developed several materials and resources they use for the topic. Nevertheless, this year, they welcomed that they could develop new, innovative resources and take a new approach to present the topic. The use of iPads and the Our Story app enabled them to capture the real, lived perspectives of elderly members of the community. The possibility to take pictures, audio-record elders' narratives and complement them with short texts, as illustrated in the story here, was an invaluable resource in the project. It added to the history collection and also provided a meaningful topic to practice children's writing (relevant for the English class). Furthermore, the direct contact with the community members added an important layer of authenticity and relevance to the Remembrance topic for the children. As one of the teachers commented: 'I can explain and go on about this for days but it's only when they [the children] hear it from the people who lived the war that they really understand the significance... like when Marielle [pseudonym] told them about how she never had bananas they began to see the relevance of it [the history] to their own lives'. Examples like this directly relate to the importance of authenticity where a personal account becomes a powerful tool for engaging children in reflection and introspection. In our classroom observations, we noticed several instances of children's increased awareness of the significance of war to everyday life and their increased use of the iPads for information-gathering and documentation. Children used the iPads to search for more information online, including information about the availability of fruit and vegetables during and after WWII in Britain. After they heard Marielle's story, children also downloaded pictures of fruit and added them to their multimedia stories. With every interview undertaken with the community members, children were taken a step back, moving backward in time in the mental memory to a past life. Yet, with every activity undertaken with the iPad, they could provide a new representation of a memory, either with a photograph, short excerpt from a historical reference or their own reflections captured as a multimedia story. This back-and-forth way of

1 "Rememberance Day marks the day World War One ended, at 11 am on the 11th day of the 11th month, back in 1918. A two minute silence is held at 11 am to remember the people who have died in wars." From http://www.bbc.co.uk/newsround/15492752 
capturing and representing memories was largely facilitated by the technological mediation, which related mainly to the multimedia and personalised nature of representation.

Authenticity in this context meant that children could flexibly combine various excerpts of audio-, textual and visual information, with no limitation of size or length for any of the data. The possibility to select, edit and share curated digital content provided an educationally sound experience for the learners. In addition, it ensured that stories shared by the elderly could be captured in their entirety, without any 'intermediary step' imposed by a pre-defined template. The possibility to have their stories captured in a visual, textual as well as audio mode meant that a high level of detail from shared narratives could be preserved and their unique character brought to the fore. Children blended pictures downloaded from the Internet with pictures taken in the class or outside the class when interviewing the elders, further adding to the past and present co-existence of the elders' memories and children's representation of them. In this way, using AirWatch and Our Story-enabled iPads, supported children to explore the relationships between personal, imagined, and documented histories. Another major theme apparent in the data was the notion of blending two seemingly opposite realities: the inter-and intra-personal nature of each partner's practices and experiences brought to the project. On many levels, children's confident use of technology was very much related to their existing practices and experiences while the elderly community members were their "anchors" and support systems. In the project, the children and elders brought these personal and shared resources together, creating a community body of knowledge and skills. Moll and colleagues (1992) first talked about the notion of culturally developed bodies of knowledge and skills in their studies of disadvantaged groups in Mexican working-class community of Tucson, Arizona. They coined the term "funds of knowledge" to refer to the bodies of knowledge and skills essential for household or individual functioning and well-being (p.133), which are often undervalued in formal learning environments, but are essential for the survival of a group. While originally the term was used to refer to the skills, strategies and information utilised by households, which may include ways of thinking and learning and practical skills, the term has been applied more widely to include various skills and knowledge individuals bring to a community. In our project, funds of knowledge blurred the communal and personal connection to war or remembrance of the war. While each partner (children or the community members) brought something different to the process of story-sharing, the final product (a personalised multimedia story), was based on their joint contribution. This relates to the theme of collaboration whereby a mutual exchange of funds of knowledge needs to happen to cocreate a shared artefact. The finished story, very much a jumble of new and old, personal and shared, has become part of the school and local archive, thus further blending the individual and community contribution and heritage. In the future it will be important to 'focus on the ways this history travels forward in time to new events through children's personal interests.' (Rowe and Neitzel, 2010, p. 193).

\section{Conclusion}

This community project is still ongoing and expanding which shows the enthusiasm of all project participants and the multiple benefits derived in the first stages.

The present and future of intergenerational projects is very much influenced by the increased access and availability of technologies in our communities. The present status quo of the use of technology in communities indicates that elderly members are often excluded from technology-related projects and feel isolated when it comes to technology use. This project attempted to directly address this gap, supporting older community members to learn more about technology by working alongside children who grew up with it. This, in turn, 
influenced the entire community, as Stef Muzz, Community Worker at Love Woburn Sands summarised: "[The interviewees] enjoyed sharing their memories but some found it very emotional and difficult. We all found it very moving and were impressed with the courtesy, pride and dignity [the children] showed during their visit." For children, the possibility to take part in a project in which elderly share their own personal narratives from the past enriches their understanding of historic events (such as WWII in this example). Importantly, it is aligned with the aim of providing children with opportunities to 'gain the competencies and dispositions that will prepare them to be creative, connected, and collaborative life-long problem solvers and to be healthy, holistic human beings who not only contribute to but also create the common good in today's knowledge-based, creative, interdependent world.'(Fullan \& Langworthy, 2014, p.2).
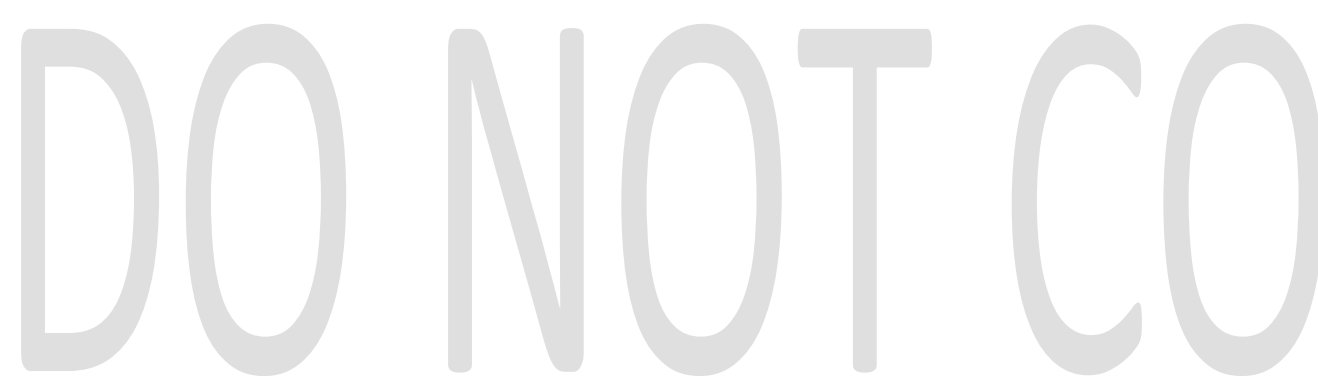


\section{References}

Ba, H., Tally, W., \& Tsikalas, K. (2002). Investigating children's emerging digital literacies. The Journal of Technology, Learning and Assessment, 1(4).

Bereiter, C., \& Scardamalia, M. (2005). Technology and literacies: From print literacy to dialogic literacy. In International handbook of educational policy (pp. 749-761). Springer Netherlands.

Campano, G. (2007). Immigrant students and literacy: Reading, writing, and remembering. New York, NY: Teachers College Press.

Falloon, G. (2013). Young students using iPads: App design and content influences on their learning pathways. Computers \& Education, 68, 505-521.

Flewitt, R., Kucirkova, N., \& Messer, D. (2014). Touching the virtual, touching the real: iPads and enabling literacy for students experiencing disability.Australian Journal of Language \& Literacy, 37(2), 107-116.

Fullan, M. \& Langworthy, M. (2014) A Rich Seam: How New Pedagogies Find Deep Learning, London: Pearson

Genishi, C., \& Dyson, A. H. (2009). Children, language, and literacy: Diverse learners in diverse times. Teachers College Press.

Gregory, E. (1996). Learning from the community: a family literacy project with Bangladeshi-origin children in London. S. Wolfendale \& K. Topping, Family Involvement in Literacy, 89-116.

Gregory, E., Long, S., \& Volk, D. (2004). Many pathways to literacy: Young children learning with siblings, grandparents, peers, and communities. Psychology Press.

Grover, S., \& Pea, R. (2013). Computational Thinking in K-12 A Review of the State of the Field. Educational Researcher, 42(1), 38-43.

Heydon, R. (2005). The de-pathologization of childhood, disability and aging in an intergenerational art class: Implications for educators. Journal of Early Childhood Research, $3(3), 243-268$.

Heydon, R. (2007). Making meaning together: Multimodal literacy learning opportunities in an intergenerational art program. Journal of Curriculum Studies, 39(1), 35-62.

Humphreys, K. (2000). Community narratives and personal stories in Alcoholics Anonymous. Journal of community psychology, 28(5), 495-506.

Jewitt, C. (2008). Multimodality and literacy in school classrooms. Review of research in education, 32(1), 241-267.

Kress, G.R. (2007). Multimodality: Exploring contemporary methods of communication. London: Routledge

Kucirkova, N., Messer, D., Sheehy, K., \& Flewitt, R. (2013). Sharing personalised stories on iPads: a close look at one parent-child interaction.Literacy, 47(3), 115-122.

Kucirkova, N., Messer, D., Sheehy, K., \& Panadero, C. F. (2014). Children's engagement with educational iPad apps: Insights from a Spanish classroom.Computers \& Education, 71, 175-184. 
Marsh, J. (2002). Electronic toys: Why should we be concerned? A response to Levin \& Rosenquest (2001). Contemporary issues in early childhood, 3(1), 132-138.

Marsh, J., Plowman, L., Yamada-Rice, D., Bishop, J. C., Lahmar, J., Scott, F., \& Winter, P. (2015). Exploring Play and Creativity in Pre-Schoolers' Use of Apps: Final Project Report.

McKee, L. \& Heydon, R. (2015). Orchestrating literacies: Print literacy learning opportunities within multimodal intergenerational ensembles. Journal of Early Childhood Literacy, 15(2), 227-255.

Mishra, P., \& Koehler, M. (2006). Technological pedagogical content knowledge: A framework for teacher knowledge. The Teachers College Record,108(6), 1017-1054.

Moll, L. C., Amanti, C., Neff, D., \& Gonzalez, N. (1992). Funds of knowledge for teaching: Using a qualitative approach to connect homes and classrooms. Theory into practice, 31(2), 132-141.

Nettles, S. M. (2005). Examining School-Community Connections Through Stones. In Phillion, J., Ming F., Connelly, M. (eds) Narrative and experience in multicultural education, 17-36.

Oulasvirta, A., \& Blom, J. (2008). Motivations in personalisation behaviour.Interacting with Computers, 20(1), 1-16.

Renando, T (in preparation). Reimagining Narratives: The Quest for Authentic Christian Spirituality (Doctoral dissertation). More available from http://www.flavoryellow.com/category/stuff-about-me/

Roberts, L. T. P. (2014). Authenticity: Theoretical considerations, instrument development, and implications for leaders. University of San Diego.

Roschelle, J. M., Pea, R. D., Hoadley, C. M., Gordin, D. N., \& Means, B. M. (2000). Changing how and what children learn in school with computer-based technologies. The future of children, 76-101.

Rowe, D. W., \& Neitzel, C. (2010). Interest and Agency in 2-and 3-Year-Olds' Participation in Emergent Writing. Reading Research Quarterly, 45(2), 169-195.

Tüzün, H., Yılmaz-Soylu, M., Karakuş, T., İnal, Y., \& Kızılkaya, G. (2009). The effects of computer games on primary school students' achievement and motivation in geography learning. Computers \& Education, 52(1), 68-77.

Vygotsky, L. S. (1987). The Collected Works of LS Vygotsky.

Whitehurst, G. J., Arnold, D. S., Epstein, J. N., Angell, A. L., Smith, M., \& Fischel, J. E. (1994). A picture book reading intervention in day care and home for children from lowincome families. Developmental Psychology, 30(5), 679.

Wohlwend, K. E. (2012). Literacy playshop: New literacies, popular media, and play in the early childhood classroom. Teachers College Press. 